\title{
Innovation and Practice of Characteristic and Multilevel Talents Training Mode
}

\author{
Shi Jin \\ School of Electrical Engineering \\ Shenyang University of Technology \\ Shenyang, China \\ wby-js@163.com \\ Guangwei Liu \\ School of Electrical Engineering \\ Shenyang University of Technology \\ Shenyang, China \\ liu-guangwei@hotmail.com
}

\author{
Ming Lin \\ School of Electrical Engineering \\ Shenyang University of Technology \\ Shenyang, China \\ xnysut@163.com \\ Dapeng Wang \\ School of Electrical Engineering \\ Shenyang University of Technology \\ Shenyang, China \\ 15004008676@139.com
}

\begin{abstract}
In order to train and transport professional and technical talents more adapted to the industry development and construction, a kind of multilevel and multi-developing talent training mode is explored for enterprise type, advanced study type, international co-culture type and so on in this paper. According to the students' personal situation and future development intentions, the appropriate academic planning is made multilevelly, the different development direction is planned for students, and the different training modes are adopted for the students with different development directions. The omnidirectional reform measures are formulated in each link of the training plan formulation, thesis topic selection, theory and experiment teaching, extracurricular technological creation activity, technological writing, language expression, academic exchange and so on. The students can be clearer to their future direction. The innovative and comprehensive talents more adapted to the needs of the society and enterprise can be trained, and the scientific research and the degree and discipline construction of school are promoted.
\end{abstract}

Keywords-higher education reform; characteristic talents training mode; multilevel; multiple development direction; degree and discipline construction

\section{INTRODUCTION}

The number of graduates (including undergraduates and postgraduates) in colleges and universities is increasing year by year. How to guarantee and improve the training quality of graduates to meet the needs of society and enterprises has become a major issue in front of us. We think to suit one's measures to local conditions and to teach students in accordance with their aptitude. According to the personal situation, the appropriate academic planning is made multilevelly and the different development direction is planned for students, in order to train and transport professional and technical talents more adapted to the industry development and construction. This paper has carried out the

This work was supported by the Education Science "Twelfth Five Year" Planning Project of Liaoning Province in China (Grant No. JG13DB072). exploration and research on "Innovation and Practice of Characteristic and Multilevel Talents Training Mode", which explores a kind of multilevel and multi-developing talent training mode for enterprise type, advanced study type, international co-culture type and so on.

\section{Challenges And Pressures of Chinese Higher EDUCATION}

In twenty-first century, with the globalization of economy, the internationalization of higher education, the rapid development of knowledge economy and science and technology, the adjustment and transformation of industrial structure and the popularization of higher education, Chinese higher education is facing unprecedented challenges and pressures [1]. Contradictions and confusion is particularly prominent on the running idea, objective and development path and other aspects of local colleges and universities. And all of this is reflected on the theoretical research and practice of talent training mode. Colleges and universities should pay attention to explore and cultivate the high-quality applied talent training characteristic. The demand trend and training standard of applied talents are thought and practiced. And the high-quality applied talent training mode is studied deeply and enriched continuously in the micro level of the course teaching content, methods, organization form, evaluation and security system, and so on [2].

After 30 years of reform and opening, especially in the past 10 years of rapid development, China has become a big country of higher education and has been striding forward towards the powerful country of higher education, which is becoming a basic power source for the sustainable development of Chinese science and technology. Chinese higher education has begun to come out of the stage of imitation and tracking, and has been entering into a new stage of paying equal attention to tracking and independent development from the development strategy of complete 
catch-up type. Chinese higher education has begun to affect the development of world higher education.

Talent is the first resource, and the strategy of strengthening country on talent is a national strategy established by our party and state. The Party Central Committee has always paid high attention to the talent work and seriously implemented the significant policy of respecting knowledge, labor, talent and creation. Since the 16th Party Congress, our party has held two national talent work conferences, formulated and promulgated the "decision on further strengthening the talent work" and the "national midlong-term talent development planning", and also organized a series of significant talent projects. The eighteen part report specially regards the talent work as a part to be deployed in the party construction part and puts forward the new requirements. It is clearly put forward that the strategic layout of talent priority should be implemented, and the grand scale and fine quality talent team should be established, which will enter into the powerful country of talents from the big country of talents. In the present era, the social development is changing quickly, the science and technology advances rapidly, knowledge renewal speed accelerates, and the society needs the innovative and comprehensive talents that not only firmly master the professional knowledge but also grasp the future development direction [3].

\section{REFORM GOAL}

To train the innovative and comprehensive talents is regarded as the main goal. According to the personal situation, to suit one's measures to local conditions and to teach students in accordance with their aptitude, the appropriate academic planning is made multilevelly and the different development direction is planed for students, in order to train and transport professional and technical talents more adapted to the industry development and construction, and the global reform of higher education is carried out designedly. The omni-directional reform measures are formulated in each link of the training plan formulation, thesis topic selection, theory and experiment teaching, extracurricular technological creation activity, technological writing, language expression, academic exchange and so on. A kind of multilevel and multideveloping talent training mode is explored facing to enterprise type, advanced study type, international co-culture type and so on. The students can be clearer to their future direction. The innovative and comprehensive talents more adapted to the needs of the society and enterprise can be trained, and the scientific research and the degree and discipline construction of school are promoted.

\section{MAIN CONTENT OF REFORM}

\section{A. Offer the specialty direction courses and special research experiment courses to lay the theory and practice foundation for the students' deep innovative research.}

In addition to the basic and specialized courses needed by degree, the specialty direction courses are added in the teaching, which teaches the latest technology of this subject specialty direction to make students understand and follow the development of subject frontier in time and deepen the theoretical and technical basis of research direction, in order to lay the foundation for the deep and innovative research work in this field. The ability training should be highlighted in the students' experimental teaching. The practical ability and innovative consciousness of students are trained by establishing the special research experiment courses [4]. The practical ability and experimental skill of students are improved by the three teaching links of theory teaching, experiment and special research, in order to lay the foundation for the experimental study in the thesis work. The students combine with their research direction and interest to select special subject and to have the class and study. The laboratories are open, and the students can carry out the experimental study. At the end of the courses, the special research report is submitted, the reply is carried out one by one, and finally the result is evaluated comprehensively.

\section{B. Select the thesis subject multilevelly to be beneficial to the students' future career development.}

The thesis subject selection is very important for students' training. According to the students' personal situation and job intentions, the thesis subject that is beneficial to their future career development can be selected and studied as possible. For example, for the students who need to continue their advanced studies, the research topics of subject frontier are selected, which can more promote the students' initiative in scientific research, and can provide a more extensive space for students to display their creativity. All of the National Natural Science Foundations of China are the front-subjects in the research field and need to make innovative research results, which is well combined with the innovative requirements of postgraduate theses, especially ones of doctoral theses [5].

\section{Add the cooperating training practice link with enterprise to be beneficial to students to be adapted to the enterprise needs.}

The enterprise practice training link for students should be added in training plan [6]. A large number of scientific research subjects in engineering colleges come from enterprises, especially the important electrical equipment manufacturing industry in China. The research subjects proposed by as Shenyang electric machine factory, Shenyang high voltage switch factory and so on in the progress of science and technology are all the hot research problems of the industry at home and abroad, which have great difficulty and high level. The students are encouraged to actively participate and take on part of the research task. The engineering problems are tackled and solved through the science and technology of real thing, in order to train the students' innovative spirit and practical ability to solve the engineering problems. Many students in this subject become the leaders of technology innovation in the large electrical equipment enterprises of our country through this kind of training mode, such as the chief engineer of China's largest transformer enterprise, the general manager of one of the major manufacturing enterprises of high voltage switch, the director of transformer institute mainly managing transformer industry and so on. 


\section{Strengthen the students' extracurricular technological production activities to train the universality of students' innovation ability.}

The students are actively organized to participate in the extracurricular technological creative activities. In particular, "Challenge Cup" extracurricular academic technological work competition activities used as a lever, the students are organized to take advantage of the outside class and to carry out technological production activities under the supervisor' guidance. Because the selected subject has the stronger innovation, the students' research interest and technological creative enthusiasm are stimulated in the extensive field. In the promotion of the extracurricular academic technological works and venture plan competition activities, students' enthusiasm of technological innovation and number of participants are continuously increasing, and the innovation space is expanded [7].

\section{E. Use the international cooperation relationship to send students to foreign for the international cooperation research.}

The conditions of school are limited to training students. The students have less contact with the outside world, but also lack the opportunity of international academic exchange. In order to make students especially postgraduates brave the storm and see the world, the cooperation relationship established between the schools and supervisors and the foreign is used, and a number of postgraduates are selected and send to more than ten universities of the United States, Germany, Canada, Japan, Korea, Hong Kong and other countries and regions to be engaged in the international cooperation research work in recent years, which the time is from half a year to two or three years. Through the research work in overseas, postgraduates not only improve the foreign language level and the ability of scientific research and international academic exchange, but also brave the storm, see the world, and enhance the confidence and ability of overcoming difficulties.

\section{F. Encourage and support students to write papers for academic exchange.}

In addition to the papers published in the academic journals, the students especially postgraduates should be organized to participate in the international conferences to carry out academic exchange. In particular, the international conferences are held in China, and we can support students as much as possible due to the less cost. For example, in recent years, we have organized a number of students to participate in the important international conferences related to the research field of this subject and specialty. To undertake international conferences is an excellent opportunity to develop the students' ability of organization and academic exchanges. In 2001, our university undertook the 17th International Conference on Electrical Machine and System (ICEMS' 2001). We organized students to participate in the collection of papers, the editor of symposium, the exchange of conference papers and so on to provide a rare opportunity of learn and ability training for students. In 2005, we undertook the 15th Conference on the Computation of Electromagnetic
Fields (COMPUMAG 2005), which was the first time to undertake the most influential series conferences on the international calculation electromagnetics in our country, and was another great exercise opportunity.

\section{G. Build a good academic atmosphere and train a rigorous study style for postgraduates.}

The construction of study style is an important part of higher education, which needs the education and cultivation of the regular and imperceptible influence. In order to build a good academic atmosphere, we have regularly carried out the academic exchange activities. Some research groups carry out the academic exchanges and discussion regular meetings for $1 \sim 2$ hours per week. The academic reports are made from supervisors to students in turn. The papers that will be submitted to the academic journals and international conference must be reported and checked in the research group. If there is no paper to read, they can exchange and report their phase research achievements at least once per person per semester. The regular academic exchange can not only play a role in the mutual learning and help, but also is a competitive mechanism, which is beneficial to the training of good study style and the advance of academic level for postgraduates.

\section{IDEAS AND METHODS OF REFORM}

According to the students' personal situation and future development intentions, the students are multilevelly divided into enterprise type, advanced study type, international coculture type and so on, and the different training modes are adopted for the students with different development directions. For the enterprise type, the cooperating training practice link with enterprise is added to be beneficial to students to be more adapted to the enterprise needs. For the advanced study type, the research topics of subject frontier are selected, which is beneficial to promote the students' initiative in scientific research and can provide a more extensive space for postgraduates to independently display their creativity. For the international co-culture type, the cooperation relationship established between the schools and supervisors and the foreign is used to send students to foreign to be engaged in the international cooperation research, which can improve the foreign language level and the ability of scientific research and international academic exchange for students.

\section{RESUlts of PROFESSIONAL TALENT TRAINING}

School of electrical engineering in Shenyang University of Technology has three undergraduate specialties including electrical engineering and automation, automation, and biomedical engineering. Electrical machines and appliances, electric drive and automation, industrial automation, high voltage and insulation technology, electrical theory and new technology, biomedical engineering and other disciplines got the grant right of master degree in 1984, 1990, 1993, 1998, 2000 and 2005 respectively. The disciplines of electrical machines and electrical appliances got the grant right of doctor degree in 1990 and 1996 respectively. The first class discipline of electrical engineering got the grant right of doctor degree in 2003. Electrical discipline is the key discipline of 
Liaoning Province. The school set the postdoctoral research station of electrical engineering. The discipline of electrical machines and appliances was listed as the national key discipline by the Ministry of Education. At present, the school has seven doctor degrees including electrical machines and appliances, power electronics and electric drive, high voltage and insulation technology, electrical theory and new technology, electric power system and automation, artificial intelligence and motion control, and medical electromagnetic engineering, and a first class discipline master degree of biomedical engineering.

After the development of half a century, especially after the construction of the national key discipline of electrical machines and appliances, the talent training level, discipline academic level and hardware facilities of electrical engineering and automation specialty all reach a new step. In recent years, a large number of professional and technical talents oriented to the society and enterprise need are trained and transported for the construction and development of industry. It has become a talent training base with strong engineering ability. The ability of undertaking the national significant research subjects and large engineering projects is promoted greatly. The fruitful results have been achieved in the discipline construction, teachers, teaching and research, outside school base, international cooperation relationship and other aspects.

From 1990 to now, electrical engineering and automation specialty relies on the advantages of the northeast old industrial base and equipment manufacturing industry base, and the deep cooperation and training are carried out in the related fields of transformer, electrical machine, electrical appliances and so on. Some enterprises are taken as the main training bases, such as TBEA Shenyang Transformer Group Co., Ltd., Tieling Power Plant, Liaoning Wanjia Electric Power Construction Group Co., Ltd., Liaoning Dongsheng Anxin Electric Control Technology Co. Ltd, Haicheng Three Fish Pump Co., Ltd., Shenyang Transformer Co., Ltd., and so on. Some enterprises are taken as the production practice units for student, such as New Northeast Electric Group (Shenyang) High Voltage Switch Co., Ltd., Harbin Electric Corporation, China First Automobile Group Corporation, Haicheng Three Fish Pump Co., Ltd., Northeast Power Transmission Equipment Group, Fushun Electric Porcelain Factory, and so on. The engineering talents can be trained according to the general and industry standards, and the engineering and innovation ability of students can be strengthened.

In 2001, the discipline successfully hosted the 17th International Conference on Electrical Machine and System (ICEMS' 2001) in Shenyang. The conference was first listed in the series conferences of IEEE, and all the papers were embodied by the international important retrieval. In 2005, the discipline successfully undertook the 15 th Conference on the Computation of Electromagnetic Fields (COMPUMAG 2005) again. The conference was first held in China, and 310 overseas scholars attended the meeting. After reviewing, 246 papers were published in the IEEE Transactions on Magnetics, and were all retrieved by SCI and EI. The discipline academic reputation is continuously improved.

At present, we have the specific and deep cooperation and exchange with the United States, Japan, Germany, Britain, Canada, Korea and other universities. The multilevel scientific research cooperation and personnel exchanges are developed. Three foreign university scholars, such as Fukuda Toshio of Nagoya University and so on, are as the part-time professors in the discipline. In recent years, a number of postgraduates are selected and send to more than ten universities of the United States, Germany, Canada, Japan, Korea, Hong Kong and other countries and regions to be engaged in the international cooperation research work, which the time is from half a year to two or three years.

The discipline will further establish the educational idea of "facing the industry, facing the future and facing the world". With the social needs as the guidance, focus on improving the innovation consciousness and comprehensive practical ability of students.

\section{REFERENCES}

[1] X.Z. Gao, "State and review on 30 years of higher education development strategies," Higher Education (Research \& Evaluation), no. 5, pp. 37-44, 2009.

[2] S.X. Zhang and Y.P. Li, "Research on the reform of undergraduate application-oriented talent cultivation mode," Higher Education Forum, no. 10, pp. 5-8, October 2010.

[3] X.M. Zhou, "The reform of our country's higher education (science and engineering) oriented towards the social needs," Journal of Higher Education Research, vol. 32, no. 1, pp. 4-6, March 2009.

[4] A.P. Wu and H. Xing, "Exploration and practice on training mode of applied innovative undergraduates," Journal of Changchun University, vol. 21, no. 12, pp. 131-134, December 2011.

[5] L. Zhang, Z.D. Qian, and T.A. Liu, “A tentative mode of undergraduategraduate education in research universities," Journal of Southeast University (Philosophy and Social Science), vol. 15, no. 4, pp. 127-130, July 2013.

[6] H.D. Wang and X. Xia, "A preliminary research on the training mode of talents majoring in science and technology of colleges and universities by means of school-enterprise collaboration," Journal of Nanchang Hangkong University(Social Sciences), vol. 15, no. 1, pp. 110-114, March 2013.

[7] Y.Q. Fu, S. Wang, and L. Yu, "Discussion on cultivation of innovative talents," Experimental Technology and Management, vol. 29, no. 7, pp. 8-10, July 2012. 